\title{
EVALUATION OF DISTAL FOREARM FRACTURES USING THE AO 2018 CLASSIFICATION
}

\section{AVALIAÇÃO DAS FRATURAS DA EXTREMIDADE DISTAL DO ANTEBRAÇO PELA CLASSIFICAÇÃO AO 2018}

\author{
Alysson Figueiredo Nogueira, ${ }^{1}$ Lucas Moratelli, ${ }^{1}$ Marcela dos Santos Martins, ${ }^{2}$ Ricardo Torres IUPI, ${ }^{2}$ \\ marcos Felipe Marcatto de abreu, ${ }^{3}$ JoÃo Carlos Nakamoto ${ }^{3}$ \\ 1. Universidade Estadual de Campinas (UNICAMP), Hospital de Clínicas, Hand Surgery, Campinas, São Paulo, SP, Brazil. \\ 2. Universidade Estadual de Campinas (UNICAMP), Hospital de Clínicas, Orthopedics and Traumatology, Campinas, São Paulo, SP, Brazil. \\ 3. Universidade Estadual de Campinas (UNICAMP), Hospital de Clínicas, Hand and Microsurgery Group, Campinas, São Paulo, SP, Brazil.
}

\section{ABSTRACT}

Objective: Distal forearm fractures are among the most common upper limb fractures in all ages, and many classifications have been proposed to describe them. Recently, a new version of AO/OTA classification was proposed. The aim of this study is to use the AO/OTA 2018 classification to report the epidemiology of distal forearm fractures in adults treated at a single center. Methods: A retrospective analysis of the initial radiographs obtained from cases of distal forearm fractures in an orthopedic emergency room at a single tertiary hospital. Results: Three hundred twenty-two cases were studied, aged $50.35 \pm 18.98$ years, $55.3 \%$ were female and $44.7 \%$ were right-sided. Type 2R3A, 2R3B and 2R3C fractures corresponded to $32.3 \%, 18.0 \%$ and $48.4 \%$ of the cases, respectively. Distal ulnar fracture was present in $41.9 \%$. There was a correlation between age and sex: $78.3 \%$ of the subjects aged under 30 years were male, and $80.6 \%$ of those aged over 60 years were female $(p<0.001)$. Conclusion: The most common type of radial fractures was $2 \mathrm{R} 3 \mathrm{C}$, and the most common type of ulna fracture was 2U3A1.1. There was a correlation between age and sex. Level of evidence IV, Case-series.

Keywords: Radius Fractures. Ulna Fractures. Wrist Injuries.

\section{RESUMO}

Objetivo: As fraturas distais do antebraço são uma das mais comuns do membro superior em todas as idades, e muitas classificações foram propostas para descrevê-las. Atualmente, uma nova versão da classificação AO/OTA foi proposta. O objetivo deste estudo foi utilizar a classificação AO/OTA 2018 para descrever a epidemiologia das fraturas distais do antebraço no adulto tratadas em um único centro. Métodos: Estudo retrospectivo, em que se avaliaram as radiografias obtidas no primeiro atendimento dos casos de fraturas da extremidade distal do antebraço de esqueletos maduros, atendidas no pronto-socorro ortopédico de um único hospital terciário. Resultados: Foram estudados 322 casos, com média da idade de 50,35 \pm 18,98 anos, 55,3\% do sexo feminino e $44,7 \%$ do lado direito. As fraturas do tipo $2 R 3 A, 2 R 3 B$ e $2 R 3 C$ corresponderam a $32,3 \%, 18,0 \%$ e $48,4 \%$, respectivamente. A ulna distal foi envolvida em 41,9\%. Houve correlação entre a idade e o sexo, de modo que, no grupo etário com idade até 30 anos, 78,3\% eram do sexo masculino e, acima dos $60,80,6 \%$ do sexo feminino $(p<0,001)$. Conclusão: As fraturas do tipo $2 R 3 C$ foram as mais comuns do rádio, e as 2U3A1.1 foram as mais comuns da ulna. Houve correlação entre idade e sexo. Nível de evidência IV, Série de casos.

Descritores: Fraturas do rádio. Fraturas da ulna. Traumatismos do Punho.

Citation: Nogueira AF, Moratelli L, Martins MS, lupi RT, Abreu MFM, Nakamoto JC. Evaluation of distal forearm fractures using the ao 2018 classification. Acta Ortop Bras. [online]. 2019;27(4):220-2. Available from URL: http://www.scielo.br/aob.

\section{INTRODUCTION}

Distal radius fracture has been described as accounting for $25 \%$ of fractures in childhood and $18 \%$ in the elderly, making it one of the most common fractures of the upper limb in all ages. ${ }^{1,2}$

Numerous classification systems have been proposed to describe fractures of the distal end of the forearm. The main classification criteria are the presence of deviations, the degree of comminution, the type of joint involvement, and ulnar involvement. ${ }^{3-6}$ The classification system with the highest reproducibility was the $\mathrm{AO}$ classification system, when categorized up to subtypes A, B and C. ${ }^{7}$ Computed tomography did not appear to contribute to higher reproducibility in all cases. ${ }^{8}$ The AO classification system is an important and widely accepted system worldwide. Until recently, few studies have described the epidemiology of fractures from the viewpoint of the new 2018 AO/OTA classification. ${ }^{9}$ Therefore, the aim of this study is to use the 2018 AO/OTA classification to describe the epidemiology of distal fractures of the forearm managed at a single healthcare center in two distinct time periods.

All authors declare no potential conflict of interest related to this article.

Work conducted by the Hand and Microsurgery Group, Hospital de Clínicas, Universidade Estadual de Campinas, Campinas, SP, Brazil.

Correspondence: Lucas Moratelli. Rua Tessália Vieira de Camargo, 126, Cidade Universitária, Campinas, SP, Brazil. 13083-887. lucasmoratelli@hotmail.com 


\section{MATERIALS AND METHODS}

This was a retrospective observational study that evaluated radiographies obtained from the orthopedic emergency center of a single tertiary care hospital providing care for patients with fractures of the distal end of the forearm. It includes both cases where the patient sough medical care spontaneously, and referred patients. The development of the study followed the STROBE (Strengthening the Reporting of Observational Studies in Epidemiology) protocol and was approved by the Research Ethics Committee, under CAAE number 91232817.8 .0000 .5404$.

Age, sex, side of the fracture and fracture classification were described according to the 2018 AO Foundation criteria. To avoid measurement bias, distal radius fracture was described up to sublevel "ABC", which was reported as having the highest reproducibility in the previous version of this classification. The classification was based on simple radiography of the wrist in the posterior-anterior (PA) and lateral views. For this purpose, images obtained before and after reduction were used. During the fracture classification process, the patient's demographic data were duly concealed. Cases in which fractures of the distal end of the forearm in skeletally mature individuals were seen during two time periods (from January to December of 2014; and from January to December of 2017) were included in the study. Cases without good quality radiographs at the time of the initial treatment, and those who had received initial care at another healthcare center and therefore did not have the initial radiographic images filed in the Radiology Unit of the institution, were excluded from the study. The need to sign an informed consent form was waived by the Research Ethics Committee.

The categorical variables were analyzed by the chi-square and Fisher's exact tests, according to the type of fracture. Numerical variables were analyzed by central tendencies, and dispersions by the Student's t-test or the Mann-Whitney test, depending on the nature of distribution. The Shapiro-Wilk test was used for analysis of normality.

Descriptive and inferential analyses were obtained using the $\mathrm{IBM}^{\circledR}$ SPSS ${ }^{\circledR}$ Statistics software version 24 , admitting a significance level of $5 \%$.

\section{RESULTS}

Four hundred and twenty-nine fractures of the distal end of the forearm were identified during the period analyzed. Of these, 87 individuals were excluded because they were skeletally immature (72 cases in 2017 and 15 cases in 2014). Another 20 cases were excluded due to the poor quality of the radiographs, which made it impossible to classify the fractures. Finally, 322 cases were studied, 189 of which were managed in 2014 and 133, in 2017.

The mean patient age was $50.35 \pm 18.98$ years, ranging from 17 to 92 years. Female patients accounted for $55.3 \%$ of the cases and the right side was affected in $44.7 \%$ of the cases.

Distal radius fractures accounted for $98.7 \%$ of the cases. Of these, type 2R3A fractures accounted for $32.3 \%$; type $2 \mathrm{R} 3 \mathrm{~B}$, for $18.0 \%$; and type 2R3C, for 48.4\%. Two participants had bilateral fractures. Distal ulnar fracture occurred in $41.9 \%$, and fracture of the tip of the styloid process was the most prevalent type (2U3A1.1), with $30.7 \%$, followed by fractures of the base of the styloid process (2U3A1.2), with 7.1\%; simple extra-articular fractures (2U3A2), with 3.5\%; and multifragmentary extra-articular fractures (2U3A3), with $0.6 \%$. The more severe the ulnar fracture, the more severe the associated radius fracture $(p=0.011)$.

There was no difference in mean patient age according to type of fracture $(p=0.077)$. However, there was a correlation between the age and sex of the participants. In the 30 years and under age group, $78.3 \%$ of individuals were male, while in the over 60 years age group, $80.6 \%$ were female $(p<0.001)$. Stratifying by age, there was no correlation between type of fracture and sex (Figure 1). Demographic data (sex and age) were similar in both periods analyzed. The rate of distal ulnar fracture was lower in 2017 than in 2014 (Table 1).

\section{DISCUSSION}

There are many different classification systems to describe distal radius fractures, but none is capable of summarize each of the descriptive characteristics in isolation, or providing guidance on treatment and inferring the prognosis. ${ }^{10,11}$

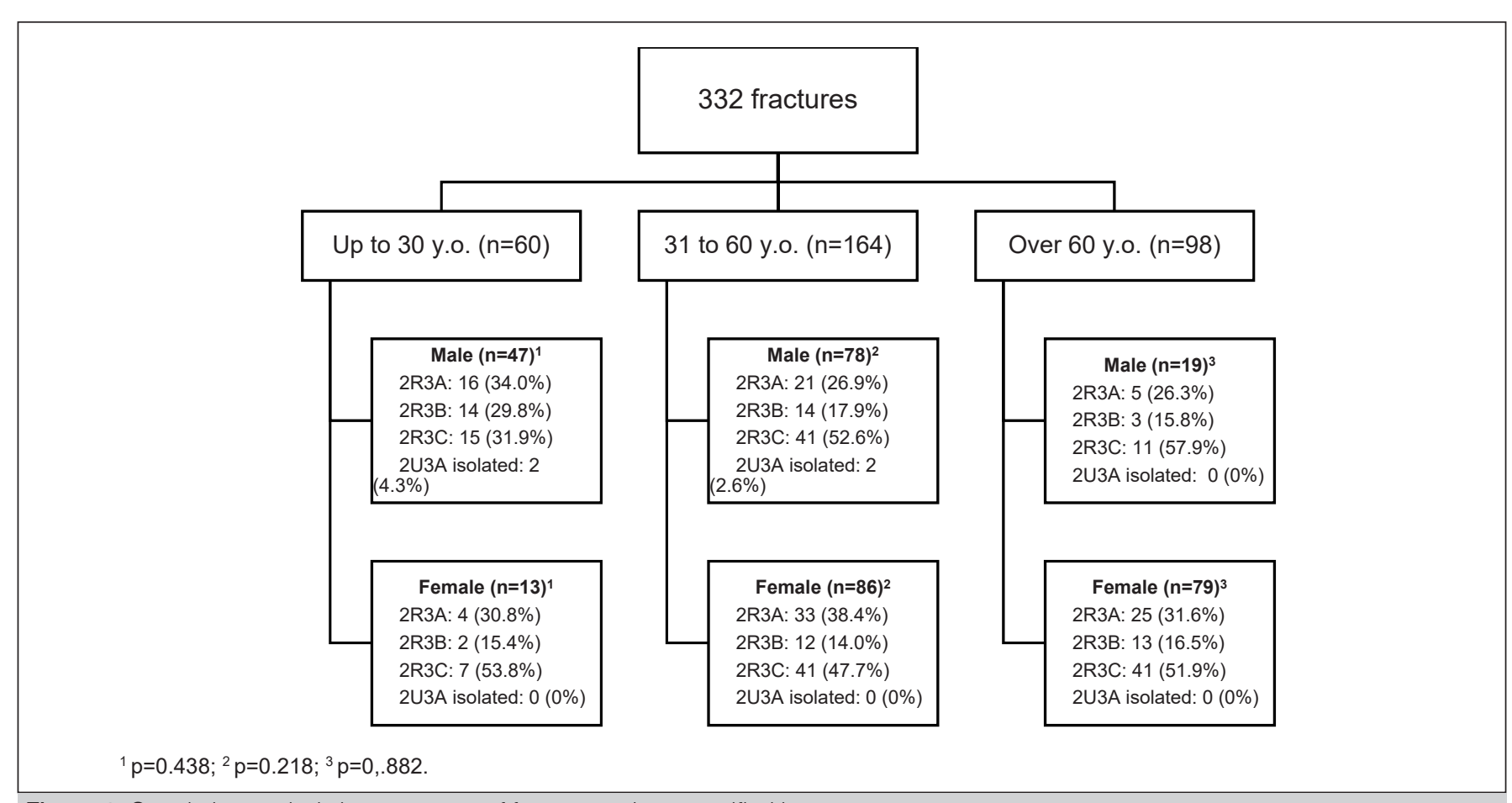

Figure 1. Correlation analysis between type of fracture and sex stratified by age. 
Table 1. Demographics and fracture characteristics between 2014 and 2017.

\begin{tabular}{|c|c|c|c|}
\hline & \multicolumn{2}{|c|}{ Year } & \multirow{2}{*}{$\mathrm{p}$-value } \\
\hline & 2014 & 2017 & \\
\hline \multicolumn{4}{|l|}{ Age } \\
\hline Up to 30 y.o & $33(17.5 \%)$ & $27(20.3 \%)$ & \multirow{3}{*}{$0.675^{*}$} \\
\hline 31 to 60 y.o. & $100(52.9 \%)$ & $64(48.1 \%)$ & \\
\hline Over 60 y.o. & $56(29.6 \%)$ & $42(31.6 \%)$ & \\
\hline \multicolumn{4}{|l|}{ Sex } \\
\hline Male & $84(44.4 \%)$ & $60(45.1 \%)$ & \multirow{2}{*}{$0.905^{*}$} \\
\hline Female & $105(55.6 \%)$ & $73(54.9 \%)$ & \\
\hline \multicolumn{4}{|c|}{ AO classification } \\
\hline 2R3A & $64(33.9 \%)$ & $40(30.1 \%)$ & \multirow{4}{*}{$0.211^{*}$} \\
\hline 2R3B & $27(14.3 \%)$ & $31(23.3 \%)$ & \\
\hline 2R3C & $96(50.8 \%)$ & $60(45.1 \%)$ & \\
\hline 2U3A isolated & $2(1.1 \%)$ & $2(1.5 \%)$ & \\
\hline \multicolumn{4}{|c|}{ Ulnar involvement } \\
\hline Intact & $101(53.4 \%)$ & $86(64.7 \%)$ & \multirow{2}{*}{$0.044^{*}$} \\
\hline Fractured & $88(46.6 \%)$ & $47(35.3 \%)$ & \\
\hline
\end{tabular}

* Pearson's Chi-squared.

Koo et al. identified that males are more affected by fractures of the distal end of the forearm. ${ }^{12}$ Although the current study observed that the majority of cases under 30 years of age were men, women were more globally affected. Furthermore, this study identified a significant increase in the proportion of women over 60 years of age who were affected. This data is described by other authors, who have identified an increasing incidence of these fractures in females over the age of $65 . .^{13}$ The coexistence of fractures of the radius and distal ulna was lower than the $58 \%$ described by May et al. ${ }^{14}$ Among the changes observed in the 2018 AO/OTA classification, we highlight the separation between radius and ulnar fracture classifications, and the creation of a qualification to describe distal radius-ulnar joint (DRUJ) instability in type $2 \mathrm{R} 3 \mathrm{C}$ radius fractures. These changes allowed for a larger number of combinations and enhanced the power of fracture description, which may have led to a classification of DRUJ instability. The 2018 version of the classification also includes the physical evaluation.

Ulnar styloid fractures are associated with DRUJ injuries, due to the important anatomic role of the ulna in the formation of the triangular fibrocartilage complex. ${ }^{15}$ In view of this, some authors have recommended management of the fracture of the styloid process of the ulna, and have identified differences in functional outcomes depending on whether or not ulnar styloid fracture is concomitantly present with distal radius fracture. ${ }^{16}$ Nevertheless, recent meta-analyses have demonstrated that there is no difference in functional outcomes between individuals with or without associated fracture of the ulna in its different presentations. ${ }^{17,18}$ Furthermore, none of the parameters of a simple radiography was shown to be a good predictor of triangular fibrocartilage injury. ${ }^{19}$

Another pertinent observation concerning the new classification is that it maintains the descriptive criteria for articular fractures of the distal radius. Therefore, its high level of complexity may affect its reproducibility, as observed in the previous version of the classification.,20 This study has some limitations. Since this was a descriptive study of first-aid radiographies obtained from a Radiology Image Database, it was outside the scope of this study to describe other clinical data, such as the trauma mechanism, associated lesions, type of treatment administered, and outcomes during follow-up. Finally, apart from radiography, no other diagnostic methods were used to aid in fracture classification, due to their lack of uniform availability in all cases.

\section{CONCLUSION}

The most common type of radial fractures was complete articular fractures (2R3C), and the most common type of ulna fracture was fracture of the tip of the styloid process (2U3A1.1). Males under 30 years of age are more prone to suffer these fractures, while females over 60 year of age are more prone.

AUTHORS' CONTRIBUTIONS: Each author made significant individual contributions to this manuscript. AFN (0000-0003-3249-8096)*. MSM (0000-00020502-586X)* and RTI (0000-0001-9573-0134)*: collected data and contributed to the concept and design of the article; LM (0000-0002-6584-5333)*: drafted the text, analyzed the data and conducted the statistical analysis; MFMA (0000-0002-9515-0540)* and JCN (0000-0003-4780-827X)*: participated in drafting and revising the text. *ORCID (Open Researcher and Contributor ID).

\section{REFERENCES}

1. Almugren TS, Al-Namlah A, Alkubaidan F, Alotaibi H, Alzimami I. Epidemiology and patterns of the hand and distal forearm fractures at King Abdul-Aziz Medical City, Riyadh, KSA. J Taibah Univ Med Sci. 2016;11(1):86-90.

2. Nellans KW, Kowalski E, Chung KC. The epidemiology of distal radius fractures. Hand Clin. 2012;28(2):113-25.

3. Frykman G. Fracture of the distal radius including sequelae--shoulder-hand-finger syndrome, disturbance in the distal radio-ulnar joint and impairment of nerve function. A clinical and experimental study. Acta Orthop Scand. 1967:Suppl 108:3+

4. Melone CP Jr. Articular fractures of the distal radius. Orthop Clin North Am. 1984;15(2):217-36.

5. Marsh JL Slongo TF Agel J, Broderick JS, Creevey W DeCoster TA et al. Fracture and dislocation classification compendium - 2007: Orthopaedic Trauma Association classification, database and outcomes committee. J Orthop Trauma. 2007;21(10 Suppl):S1-133.

6. Fernandez DL. Distal radius fracture: the rationale of a classification. Chir Main. 2001;20(6):411-25.

7. Kreder HJ, Hanel DP, McKee M, Jupiter J, McGillivary G, Swiontkowski MF. Consistency of $\mathrm{AO}$ fracture classification for the distal radius. J Bone Joint Surg Br. 1996;78(5):726-31.

8. Arealis G, Galanopoulos I, Nikolaou VS, Lacon A, Ashwood N, Kitsis C. Does the CT improve inter- and intra-observer agreement for the AO, Fernandez and Universal classification systems for distal radius fractures? Injury. 2014;45(10):1579-84.

9. AO Foundation. Fracture and Dislocation Compendium-2018. J Orthop Trauma. 2018;32(1 Suppl)

10. Oliveira-Filho OM de, Belangero WD, Teles JBM. Fraturas do rádio distal: avaliação das classificaccões. Rev Assoc Med Bras. 2004;50(1):55-61.

11. Siripakarn Y, Niempoog S, Boontanapibul K. The comparative study of reliability and reproducibility of distal radius $\square$ fracture classification among: AO frykman and Fernandez classification systems. J Med Assoc Thai. 2013;96(1):52-7.

12. Koo KOT, Tan DMK, Chong AKS. Distal radius fractures: an epidemiological review. Orthop Surg. 2013;5(3):209-13.

13. Baron JA, Karagas M, Barrett J, Kniffin W, Malenka D, Mayor M, et al. Basic epidemiology of fractures of the upper and lower limb among Americans over 65 years of age. Epidemiology. 1996;7(6):612-8.

14. May MM, Lawton JN, Blazar PE. Ulnar styloid fractures associated with distal radius fractures: Incidence and implications for distal radioulnar joint instability. J Hand Surg Am. 2002;27(6):965-71.

15. Kwon BC, Seo BK, Im H-J, Baek GH. Clinical and radiographic factors associated with distal radioulnar joint instability in distal radius fractures. Clin Orthop Relat Res. 2012;470(11):3171-9.

16. Belloti JC, Moraes VY, Albers MB, Faloppa F, Dos Santos JBG. Does an ulnar styloid fracture interfere with the results of a distal radius fracture? J Orthop Sci. 2010;15(2):216-22.

17. Mulders MAM, Fuhri Snethlage LJ, de Muinck Keizer RJO, Goslings JC, Schep NWL. Functional outcomes of distal radius fractures with and without ulnar styloid fractures: a meta-analysis. J Hand Surg Eur Vol. 2018;43(2):150-7.

18. Yuan $\mathrm{C}$, Zhang $\mathrm{H}$, Liu $\mathrm{H}$, Gu J. Does concomitant ulnar styloid fracture and distal radius fracture portend poorer outcomes? A meta-analysis of comparative studies. Injury. 2017;48(11):2575-81.

19. Kasapinova K, Kamiloski V. The correlation of initial radiographic characteristics of distal radius fractures and injuries of the triangular fibrocartilage complex. $J$ Hand Surg Eur Vol. 2016;41(5):516-20.

20. van Leerdam RH, Souer JS, Lindenhovius ALC, Ring DC. Agreement between Initial Classification and Subsequent Reclassification of Fractures of the Distal Radius in a Prospective Cohort Study. Hand (N Y). 2010;5(1):68-71. 